\title{
A TERCEIRA ÉPOCA DA ANÁLISE DE DISCURSO DE MICHEL PÊCHEUX E AS CONFIGURAÇÕES CONTEMPORÂNEAS DA SUBJETIVIDADE: ENTRE O DISCURSO DA CIÊNCIA, O DISCURSO DO CAPITALISMO E A PSICANÁLISE
}

RESUMO: Este artigo pretende problematizar uma interface entre a intervenção de Michel Pêcheux de 1983 (O discurso: estrutura ou acontecimento) e algumas questões psicanalíticas contemporâneas sobre os efeitos da "dominação combinada" de dois discursos: o discurso da ciência e o discurso do capitalismo. Pêcheux, em um diálogo com a psicanálise, problematiza as consequências dessa combinação discursiva, denunciando como efeito uma instabilidade lógica da singularidade do sujeito. O pragmatismo do sujeito contemporâneo, expressão do autor, busca apagar a singularidade estruturante do sujeito. Para Ansermet, psicanalista francês, esse neo-positivismo forma uma das epistemes maiores do nosso tempo. Ansermet, assim como fez Pêcheux três décadas antes, situa o centro desse debate no cientificismo contemporâneo. Dessa forma, ilumina-se determinados pontos da última construção teórica de Pêcheux que legitimam a interface entre o campo discursivo e o campo psicanalítico, assim como pontos da reflexão pecheutiana que problematizam a questão do cientificismo no mundo atual.

Palavras-chave: Discurso. Psicanálise. Sujeito. Singularidade.

\section{Algumas considerações sobre a interface entre Análise do Discurso e Psicanálise}

O presente artigo apresenta uma reflexão de ordem teórica e historiográfica, fundada na articulação entre Análise do Discurso e Psicanálise, sobre o estatuto da subjetividade na época denominada por historiadores, sociólogos e psicanalistas de pós-modernidade. Em uma breve contextualização, a pós-modernidade, iniciada no fim do século XX, é marcada pelo ocaso das ideologias que estruturam a civilização, como consequência da dominação combinada de dois discursos: o discurso da ciência e o discurso do capitalismo. Este artigo pretende, então, articular uma discussão, ancorada fundamentalmente na última intervenção de Pêcheux em 1983 ( $O$ discurso: estrutura ou acontecimento) e em determinados postulados do psicanalista François Ansermet (em Elogio do incomensurável, texto de 2013), com o intuito de interrogar sobre como se estrutura o sujeito na pós-modernidade ou contemporaneidade. Conforme será discutido nas próximas páginas, a reflexão sobre as novas

\footnotetext{
*Pós-doutorando em Estudos Linguísticos pela UFMG. E-mail: b_machado@uol.com.br.
} 
formas de subjetividade é de grande pertinência para a Análise do Discurso, em sua condição de práxis, poder renovar e atualizar a sua condição de discurso, sem perder de vista o sujeito concebido como "efeito de linguagem". A chamada "terceira época da Análise do Discurso", fundamentalmente o último texto pecheutiano, constitui a ponte de articulação entre discurso, psicanálise e os questionamentos sobre as configurações contemporâneas da subjetividade.

Articular a Psicanálise ao campo da Análise do Discurso é um gesto inaugural da/na AD. A própria fundação da disciplina por Michel Pêcheux, em 1969, implica uma aliança com o campo psicanalítico. Como nos lembram Pêcheux e Fuchs (1990), o empreendimento da Análise Automática do Discurso, primeira fase da $\mathrm{AD}$, reside na articulação de três regiões do conhecimento científico: o materialismo histórico (com Althusser e sua releitura de Marx), a linguística (com o movimento estruturalista) e a teoria do discurso. Essas três regiões, por sua vez, são atravessadas e articuladas por uma teoria do sujeito de natureza psicanalítica (com Lacan, a partir de seu "retorno a Freud"). Em uma interessante convergência histórica, foi justamente em 1969, ano da publicação da AAD de Pêcheux, que Lacan transfere seu seminário anual para a Faculté de Droit, próximo ao Pantheon, após sua expulsão da Ecole Normale Supérieure. O seminário em questão é o Seminário 17: O avesso da psicanálise. O nascimento da $\mathrm{AD}$ e a transferência de Lacan para a Faculdade de Direito são ambos uma consequência lógica da situação política na França nos meses pós maio de 68 .

De acordo com Maingueneau (1990, p.69): "Nos fins dos anos 60 a frente do palco intelectual estava ocupada ao mesmo tempo pelo marxismo, pela psicanálise e pelo estruturalismo." Ao tratar mais especificamente sobre o lugar da Psicanálise nesse momento histórico, Gadet et alii (1990) comentam que a vasta coletânea intitulada Escritos, publicada por Lacan em 1966, se tornaria, mais que qualquer outra obra publicada na época, o livro de cabeceira de toda uma geração de intelectuais franceses. Esse livro, que conta com quase mil páginas, reúne intervenções e artigos redigidos por Lacan entre 1936 e 1966, ano em que redige o texto que encerra o referido volume e cujo tema é de grande relevância para este artigo: A ciência e a verdade. O texto em questão é evocado por Pêcheux na obra Semântica e discurso: uma crítica à afirmação do óbvio, de 1975.

No percurso dessa obra, vemos Pêcheux fazer um balanço e uma retomada crítica da tríplice aliança marxismo/psicanálise/estruturalismo, em um movimento de conjunção e disjunção dos fundamentos sobre a teoria da ideologia herdada de Althusser. Em sua retificação de $1978^{1}$, Pêcheux tece uma autocrítica e aponta que a insubmissão ideológica teve por consequência uma tendenciosa indistinção entre o sujeito (simbólico) e o eu (imaginário) no corpo teórico de sua própria obra. Em suas palavras: "[...] a ordem do inconsciente não coincide com a ideologia, o recalque não se identifica nem com o assujeitamento nem com a repressão, mas isso não significa que a ideologia deva ser pensada sem referência ao registro do inconsciente." (PÊCHEUX, 1988, p. 301)

Essa tensão entre a ordem da ideologia e a teoria do inconsciente pode ser encontrada na própria Análise Automática do Discurso de 1969, primeira fase da AD. De acordo com Henry (1990), Pêcheux busca provocar uma ruptura no campo ideológico das "ciências sociais" pela via do discurso e da análise do discurso, construindo um dispositivo experimental que é a Análise Automática do Discurso. A ligação muito evidente entre prática política (e ideológica) e discurso (lugar do sujeito de inspiração psicanalítica), nessa primeira

\footnotetext{
${ }^{1}$ Só há causa daquilo que falha ou o inverno político francês: início de uma retificação. Publicado como anexo em Semântica e Discurso: uma crítica à afirmação do óbvio, obra de 1975.
} 
fase, é a forma que tem Pêcheux de recusar e criticar veementemente a concepção da linguagem reduzida a um instrumento de comunicação e de transmissão de informações, o que mascara sua ligação intrínseca com a prática política. De acordo com Henry: "É justamente para romper com a concepção instrumental tradicional da linguagem que Pêcheux fez intervir o discurso e tentou elaborar teoricamente, uma concepção original sobre este." (HENRY, 1990, p. 26)

Pêcheux (1990) fundamenta-se na raiz saussureana de sua formação e de seu pensamento. Em suas palavras, o deslocamento conceitual introduzido por Saussure consiste precisamente em separar a suposta homogeneidade entre a prática e a teoria da linguagem. Dando continuidade à argumentação de Pêcheux, a partir do momento em que a língua deve ser pensada como um sistema, ela deixa de ser compreendida como tendo a função de exprimir sentido. Ela se torna um objeto do qual uma ciência pode descrever o funcionamento. A metáfora saussureana do jogo de xadrez para se pensar o objeto da linguística se faz aqui pertinente, já que não se deve procurar o que cada parte significa, mas quais são as regras que tornam possível qualquer parte, quer se realize ou não.

Se a teoria da ideologia e a teoria do inconsciente estão historicamente imbricadas na constituição da AD, Orlandi (1994) lembra que Pêcheux não teve como proposta na AD produzir uma teoria do sujeito ou uma teoria da ideologia. Pêcheux, ainda nas palavras de Orlandi, diz que pela teoria do discurso se pode considerar que ideologia e inconsciente estão materialmente ligados na produção de sentidos e que a AD pode interferir no campo dessas teorias.

O denominador comum entre Análise do Discurso e Psicanálise pode ser exemplarmente demonstrado na seguinte passagem extraída de Maingueneau:

[...] a escola francesa de análise de discurso se afirma como uma "análise" (= uma psicanálise) aplicada aos textos. Há aí muito mais que uma coincidência de nomes: é a materialização de uma certa configuração do saber em que o mesmo termo "análise" funciona ao mesmo tempo sobre os registros linguístico, textual e psicanalítico. (MAINGUENEAU, 1990, p. 69)

Em O discurso: estrutura ou acontecimento, última intervenção de Pêcheux datada de 1983, o autor observa que o efeito subversivo da trilogia Marx-Freud-Saussure foi um desafio intelectual engajando a promessa de uma revolução cultural que coloca em causa as evidências da ordem humana como estritamente bio-social. Para Pêcheux, a revolução estruturalista fez pesar uma suspeita absolutamente explícita sobre o registro do psicológico (e sobre as psicologias), suspeita essa que traduz o reconhecimento de um fato estrutural próprio à ordem humana: o da castração simbólica. A divisão subjetiva é, dessa forma, irredutível ao ser falante.

Em contrapartida, não é possível negligenciar as grandes contribuições que os estudos da linguagem trouxeram para a Psicanálise, seja por meio do retorno a Freud, empreendido por Lacan via Estruturalismo de Saussure, seja por meio das próprias teorias enunciativas e discursivas. Para Ansermet: "A interrogação psicanalítica pode fazer progredir a ciência. Do mesmo modo, a psicanálise pode progredir também em afinidade, e em alteridade, com outros campos. Esse foi o método de Freud e também o de Lacan.” (ANSERMET, 2013, p. 42) 
Ansermet (2013) lembra que essa abertura ao interdisciplinar implica ir ao encontro do desejo de Freud de que a psicanálise não fosse um sistema, que permanecesse sempre inacabada, sempre pronta a rearranjar ou a modificar as suas doutrinas, seja pela prática clínica, seja pela interface com outros campos. O autor alerta ainda sobre o risco de a Psicanálise se tornar obscurantista, se escolher se isolar ou manter uma vertente conservadora: ela mantém uma relação de necessidade com outros campos que lhe são conexos, campos que constituem avanços possíveis para ela e para a sua clínica. Azevedo (2010) discorre sobre a insistência freudiana no fato de o psicanalista ter de percorrer outros campos do conhecimento, como a biologia, a história, a mitologia, a literatura e a filologia (que é a Linguística praticada no tempo de Freud). Nas palavras da autora, "Em suma, o que ele [Freud] pede, ao mesmo tempo que reconhece a dimensão utópica de sua proposta, é uma escola de formação de analistas fundada no que hoje está em voga sob o nome de interdisciplinaridade." AZEVEDO, 2010, p. 73) Posteriormente, nas décadas de 1950 e 1960, Lacan soma duas disciplinas, oriundas dos estudos da linguagem, à lista interdisciplinar elencada por Freud: as teorias discursivas e enunciativas. Maurano destaca que:

Na ótica lacaniana, o termo discurso tem lugar privilegiado. Sua teorização constitui um dos mais preciosos instrumentos existentes na investigação do que é produzido pelo sujeito e pela ordem social em que ele se insere. Para Lacan, de fato, os discursos são como o aparelho que governa tudo o que pode surgir da palavra. (MAURANO, 2010, p. 211)

O já comentado Seminário 17: O avesso da psicanálise, do biênio 1969-70, constitui o momento mais fundamental da elaboração lacaniana sobre o estatuto do discurso como uma estrutura simbólica que organiza a cultura e o campo pulsional. É neste seminário que o psicanalista desenvolve a sua teoria dos quatro discursos e abre caminho para a discussão, iniciada em 1971, sobre as condições de emergência do discurso do capitalista, conforme será discutido.

\section{Pêcheux, a Psicanálise e as configurações contemporâneas da subjetividade}

A Análise do Discurso, assim como a Psicanálise, vê-se diante de uma necessidade de renovação imposta pelas formas contemporâneas de produção e circulação de discursos. As novas conformações da subjetividade produzidas pela aliança entre o discurso da ciência e o discurso do capitalismo estão no centro desse debate iminentemente atual. Ansermet (2013) situa o centro desse debate no cientificismo contemporâneo. $\mathrm{O}$ cientificismo, para esse autor, tem uma grande proximidade com as ilusões da religião, ao se apoiar em uma crença reducionista nos resultados e nas construções da ciência. Essa "religião da ciência" se apoia nos sofismas das bases biológicas que regem o mundo contemporâneo e que produzem consequências que afetam diretamente o conceito de sujeito, um forte ponto de união entre a Análise do Discurso e a Psicanálise:

Como a ciência se transforma em ilusão? Através de qual reviravolta ela chega a se reduzir a uma crença? Com base na psicanálise, duas grandes balizas poderiam explicar essa transformação: por um lado, a ciência se 
tornaria cientificismo a partir do momento em que ela rejeita o sujeito, [sujeito] que, no entanto, foi uma das condições de sua emergência; por outro lado, ela se torna cientificismo quando rejeita seu limite, seu ponto de impossível. (ANSERMET, 2013, p. 39)

Esse "ponto de impossível" é o que Lacan denominou real, aquilo que escapa à possibilidade de a linguagem atribuir sentido e significação. Nas palavras de Pêcheux, “[...]'há real', isto é, pontos de impossível, determinando aquilo que não pode não ser 'assim', (O real é o impossível... que seja de outro modo)." (PÊCHEUX, 2012, p. 29). A Psicanálise, assim como a última época da $\mathrm{AD}$ de Pêcheux, coloca em primeiro plano a exterioridade da linguagem em relação ao real, e Lacan leva às últimas consequências essa não relação entre a linguagem e o real. Ainda de acordo com Ansermet (2013), se a Psicanálise é uma obra aberta, ela se encontra em uma relação de necessidade e de alteridade com outros campos, inclusive com a ciência, com a condição de que se trate de uma versão da ciência que mantenha em aberto a questão do seu ponto de impossível. O discurso contemporâneo das neurociências, em conformidade com o paradigma biológico, busca dar uma significação ao todo do real, recobri-lo sem deixar restos. Esse gesto tem novamente como consequência uma exclusão do sujeito e a redução a uma analogia entre função do cérebro e função psíquica.

Nas palavras de Ansermet (2013), as neurociências constroem um modelo ideal do humano, emergindo do organismo, inteiramente determinado, sem a dimensão do Outro da linguagem. É o que evidencia uma questão muito atual colocada pelo campo das neurociências: seria a realidade psíquica localizável ou mapeável? Ansermet (2013) argumenta que, contrariando as premissas das neurociências, o resultado do fato da linguagem é a perda instintual própria ao humano. De acordo com suas palavras, o homem é um vivente perturbado pelo sujeito que emerge pela operação da linguagem. Dessa forma, nada é direto no humano entre a sua suposta base biológica e sua posição subjetiva, assim como não há superposição possível ou inferência direta entre uma estrutura neuronal e uma função psíquica (subjetiva). A Psicanálise, nesse debate, sustenta uma posição que novamente a aproxima da Análise do Discurso: "A psicanálise, ao menos na orientação que lhe dá Lacan, se interessa pelo real na medida em que ele escapa. Ela se interessa pelo sujeito." (ANSERMET, 2013, p. 41)

Tal aproximação pode ser legitimada ao se atentar a determinadas passagens de Semântica e discurso: uma crítica à afirmação do óbvio, de 1975. O real que escapa à estrutura do discurso é evocado por Pêcheux ao afirmar que, especialmente no que diz respeito à semântica, o estruturalismo linguístico desemboca em um estruturalismo filosófico que tenta abarcar no explicável o resíduo inexplicável. Pêcheux parece solidário à tese de Lacan de se tomar o real como um resto impossível de ser absorvido pela estrutura do simbólico. Ao discorrer sobre as teorias semânticas estruturais e gerativas, o autor assim se expressa:

...essa perspectiva cartesiano-leibniziana, segundo a qual o sujeito falante calcula espontaneamente, encontra seu próprio limite na existência do "contexto" e da "situação", que impedem o "fechamento do sistema" por constituir um resto cuja reabsorvição é radicalmente impossível (...). $\mathrm{O}$ segundo ponto característico das teorias semânticas atuais nos é, por aí mesmo, designado, de algum modo, por dualidade: trata-se, com efeito, da 
teoria da enunciação como teoria desse resto inerente à existência do "sujeito falante" em situação... (PÊCHEUX, 1988, p. 62).

Os últimos trabalhos de Pêcheux, posteriores à já evocada retificação de $1978^{2}$, que promoveu uma maior abertura à Psicanálise e marcou o início da terceira época da $\mathrm{AD}$, voltam-se de forma mais direta para essa questão da antinomia entre linguagem e discurso em relação ao real. Em linhas gerais, a retificação promovida por Pêcheux em 1978 incide diretamente sobre uma crítica (e uma autocrítica) no que diz respeito à sua dificuldade em consentir à divisão estrutural do sujeito em nome de uma homogeneidade pragmática da teia discursiva. A interpelação ideológica do sujeito, amplamente trabalhada pelo autor, é um dos nomes desse imperativo que exige que "isso funcione". Pêcheux é então severo com sua própria obra e critica o assujeitamento da interpelação ideológica: "[...] levar demasiadamente a sério a ilusão de um ego-sujeito-pleno em que nada falha, eis precisamente algo que falha em Les Vérités de La Palice." (PÊCHEUX, 1988, p. 300) Ainda em suas palavras, a série analítica sonho-ato falho-chiste, pontos privilegiados da emergência do sujeito na estrutura, infecta constantemente a ideologia dominante. Tal fato marca o que Pêcheux nomeia de "a vitória do lapso e do ato falho nas falhas da interpelação ideológica”. (PÊCHEUX, 1988, p. 301). Pêcheux retoma suas críticas à insubmissão ideológica em sua última obra, ao trabalhar a questão da discursividade como estrutura ou como acontecimento. $\mathrm{O}$ autor não se furta em afirmar que a noção de "memória discursiva", emprestada de Foucault pela AD, derivou muitas vezes para a ideia de uma "máquina discursiva de assujeitamento" dotada de uma estrutura semiótica interna, ou seja, em uma concepção estrutural da discursividade que desembocaria em um apagamento do acontecimento (a contingência, lugar da emergência do sujeito) através de sua absorção em uma sobreinterpretação antecipadora.

Embora, em 1978, Pêcheux ainda não estivesse interrogando propriamente a questão do momento contemporâneo do rigor positivo na constituição das ciências, ele não deixa de atentar para uma certa equivalência entre o discurso científico e um uso ideológico feito do mesmo. Tal afirmação pode ser atestada por uma passagem de sua última obra, quando ele faz uma nova crítica ao movimento estruturalista. $\mathrm{O}$ autor é historicamente preciso ao apontar que o deslizamento do estruturalismo francês e seu desmoronamento enquanto "ciência régia" no início dos anos 1980 coincide com um crescimento da recepção dos trabalhos de Lacan:

Este caráter oscilante e paradoxal do registro do ordinário do sentido parece ter escapado completamente à intuição do movimento estruturalista: este nível foi objeto de uma aversão teórica, que o fechou totalmente no inferno da ideologia dominante e do empirismo prático, considerados como ponto-cego, lugar de pura reprodução de sentido. (PÊCHEUX, 2012, p. 52; grifos meus)

\footnotetext{
${ }^{2}$ Só há causa daquilo que falha ou o inverno político francês: início de uma retificação. Publicado em Semântica e Discurso: uma crítica à afirmação do óbvio, obra de 1975.

${ }^{3}$ Les Vérités de La Palice é o título original da obra Semântica e discurso: uma crítica à afirmação do óbvio.
} 
Lacan, por sua vez, chega a afirmar em A Ciência e a Verdade que a ciência é uma "ideologia da supressão do sujeito", advinda da anulação da cadeia de sentido que permeia a palavra, em nome de uma escritura algébrica. Pêcheux, por sua vez, localiza o lugar da terceira época da $\mathrm{AD}$ nas próprias falhas da ideologia e do "pragmatismo cientificista" que contamina o mundo contemporâneo, um lugar da interpretação na tessitura dos enunciados, descrito por ele como uma série de pontos de deriva possíveis. É nesse espaço que, segundo o autor, a Análise do Discurso pretende trabalhar: "A consequência do que precede é que toda descrição [...] está intrinsecamente exposta ao equívoco da língua: todo enunciado é intrinsecamente suscetível de tornar-se outro, diferente de si mesmo, se deslocar discursivamente de seu sentido para derivar para um outro." (PÊCHEUX, 2012, p. 53). O lugar das disciplinas de interpretação - e o próprio momento da interpretação nas práticas de análise do discurso, por levarem em conta o Outro das produções linguageiras e discursivas encontra-se em um lugar de alternância ou batimento em relação aos procedimentos puros de descrição.

Para o autor, em outra crítica ao Estruturalismo, ao cientificismo e aos Aparelhos Ideológicos do Estado, o "fantasma da ciência régia" é o que vem, em todos os níveis, negar o equívoco fundamental da estrutura do discurso onde se aloja o sujeito, conferindo a ilusão de que sempre se pode saber do que se fala, o que equivale a negar o próprio ato de interpretação no momento preciso em que ele aparece, já que o sujeito emerge desse e nesse mesmo ato. $\mathrm{Na}$ retificação de 1978, publicada em Semântica e Discurso, Pêcheux reconhece esse erro em mais uma autocrítica, nesta passagem: "Tudo se passa, em Les Vérités de La Palice, como se o que foi dito do sujeito se confundisse tendencialmente com o que foi posto relativamente ao ego como "forma-sujeito" da ideologia jurídica..." (PÊCHEUX, 1988, p. 299, grifos do original). Daí a conclusão do autor em sua última obra, em um decisivo consentimento à lógica do sujeito como uma resposta ao impossível do real, ao reconhecer a impossibilidade de uma identificação plenamente bem sucedida, que não seja afetada por uma "infelicidade" (no sentido performativo do termo) e um desencontro que é de estrutura.

Dando prosseguimento, sua última obra, $O$ discurso: estrutura ou acontecimento, de 1983, foi visionária ao problematizar o que Pêcheux denominou de "momento contemporâneo do rigor positivo" na constituição das ciências que, ainda em suas palavras, buscam "homogeneizar o real" ou buscam uma "cobertura lógica das regiões heterogêneas do real". Para o autor, essa homogeneização do real afeta desde a lógica matemática até os espaços administrativos e sociais, através do método hipotético-dedutivo e as técnicas de "administração de prova". Para Pêcheux (2012, p. 33, grifos meus) - o que guarda uma sintonia com as hipóteses de Ansermet -, esse "neo-positivismo" forma uma das "epistemes" maiores do nosso tempo, o que também vem a afetar o conceito de sujeito: "O sujeito pragmático (...) tem por si mesmo uma imperiosa necessidade de homogeneidade lógica." $\mathrm{O}$ "sujeito pragmático", por consequência, desconhece a "singularidade estruturante" do ser falante.

Ressonâncias do dizer de Pêcheux podem ser encontradas nas elaborações contemporâneas do campo da Psicanálise que empreendem uma reflexão sobre as consequências da aliança do discurso da ciência com o discurso do capitalismo. Em Encontros do real, Brusa (2014) afirma que a única condição para o sujeito ser acolhido na nova ordem, essa ordem marcada pelo casamento da ciência com a economia, é consentir em se tornar objeto da prática da avaliação que vem integrar, com um suplemento de racionalidade, o vazio deixado pelos princípios da tradição. Nas palavras da autora, "a 
tradição não é unívoca, tem suas raízes no discurso do Outro, está inevitavelmente exposta ao mal-entendido da interpretação. A nova ordem resolve o risco do mal-entendido com a evidência numérica." (BRUSA, 2014, p. 131, 132). Pêcheux (2012), em um diálogo com a Psicanálise, problematiza as consequências dessa dominação discursiva combinada entre o discurso da ciência e o discurso do capitalismo, denunciando como seu efeito uma "instabilidade lógica da singularidade do sujeito".

Carvalho explicita essa aliança entre ciência e capitalismo, ressaltando que se trata de uma "configuração discursiva":

Compreendemos, assim, o cientificismo de nossa época: ele é um efeito de retorno do objeto causa de desejo que foi forcluído ${ }^{4}$ do discurso da ciência, por meio da conjunção do discurso da ciência com o discurso do capitalista. Em outros termos, o cientificismo pode ser caracterizado como uma recusa do real do gozo como um impossível mediante a promoção do mais-degozar. Essa configuração discursiva, nascida da conjunção entre ciência e capitalismo, acaba por criar "um mundo povoado de latusas", como diz Lacan no Seminário 17. (CARVALHO, 2013, p. 30; grifos do original)

Ainda com Carvalho (2013), a astúcia do discurso capitalista reside na maneira como religa o sujeito ao objeto perdido (mais-de-gozar), ofertando-o como objeto de consumo, enquanto a verdade que poderia vir à luz por intermédio dessa divisão permanece escondida.

Pêcheux (2012), comentando esse "projeto de um saber" que tampona o impossível próprio do real, demonstra-se sensível e vanguardista no que diz respeito aos efeitos do discurso da ciência e do discurso do capitalismo sobre o sujeito e a subjetividade. Trata-se do que, no momento atual do século XXI, Brusa (2014) e os psicanalistas contemporâneos denominam de "nova ordem". Nas palavras de Pêcheux "... ele amarra tão bem (...) os interesses dos sucessivos mestres desse mundo (...) que o fantasma desse saber, eficaz, administrável e transmissível, não podia deixar de tender historicamente a se materializar por todos os meios." (PÊCHEUX, 2012, p. 35). O autor prossegue sua intervenção de forma irônica e provocadora: "A promessa de uma ciência régia conceptualmente tão rigorosa quanto as matemáticas, concretamente tão eficaz quanto as tecnologias materiais, e tão onipresente quanto a filosofia e a política!... como a humanidade poderia ter resistido a semelhante pechincha?" (PÊCHEUX, 2012, p. 35; grifo do original). Em um momento anterior de sua reflexão, que se articula com a discussão aqui apresentada, Pêcheux (1988) não se furta a afirmar que o discurso da ciência tem como característica o "apagamento do sujeito em sua estrutura", permanecendo, no entanto, "presente por sua ausência".

\footnotetext{
${ }_{5}^{4}$ Forcluído: rejeitado. Ver nota 7.

${ }^{5}$ Latusas: Objetos velozmente descartáveis, frutos da cultura do consumo, também conhecidos como gadgets. São ofertados pelo mercado e buscam, na concepção de Lacan, tamponar a falta estrutural do sujeito. Exemplos atuais: smartphones, tablets, iphones, etc.
} 


\section{O sujeito do contemporâneo em Pêcheux e Lacan: o declínio da subjetividade na era da avaliação}

Esse "apagamento do sujeito", expressão de Pêcheux, promovido pelo discurso da ciência é objeto de reflexão de Lacan em seu já citado texto A ciência e a verdade, de 1966. Não é excessivo relembrar novamente que esse texto é trabalhado e evocado por Pêcheux em diversos momentos da sua obra de 1975, Semântica e discurso: uma crítica à afirmação do óbvio. Nesse texto, Lacan lança um argumento que vai guiar diversos momentos do pensamento pêcheutiano após a primeira época da $\mathrm{AD}$ : a ciência rejeita a emergência do sujeito em sua estrutura. Para Lacan (1998) a ciência se sustenta no seguinte aspecto: da verdade do sujeito, como causa, ela não quer saber nada. E no lugar do sujeito como causa, a ciência utiliza-se dos saberes científicos pelo viés do discurso do mestre, dando consistência ao que Brousse (2013) denomina "discurso positivista", que faz ressonância à expressão pecheutiana "momento contemporâneo do rigor positivo". Em outros termos, as novas formas dominantes de discurso (ciência e capitalismo) rejeitam a singularidade do sujeito. No discurso positivista o saber vem ocupar o lugar do mestre, daquele que detém a resposta, sendo que o sujeito como causa, o sujeito da AD e da Psicanálise, carrega em sua estrutura um enigma, uma pergunta. Nas palavras de Brousse "... o discurso positivista se caracteriza pela importância dada ao Um." (BROUSSE, 2013, p. 68; grifo do original). Trata-se de um discurso que rejeita e sutura a divisão estrutural do sujeito em nome de um dogmatismo que enuncia: "É verdadeiro porque é científico."

Em contrapartida, do ponto de vista da Psicanálise e da Análise do Discurso que contempla o projeto pecheutiano, a verdade é inseparável dos efeitos de linguagem, efeitos esses que incluem o inconsciente. Tomando como referência o termo lacaniano Outro para conceituar o lugar do inconsciente, Pêcheux (2012) fala de um discurso-outro como uma presença virtual na materialidade discursiva, a insistência do Outro como lei do espaço social e da memória histórica. É nesse registro que trabalham as disciplinas de interpretação. O autor afirma que nos espaços das narrativas, dos discursos e dos textos, as "coisas a saber"6 coexistem com objetos a propósito dos quais ninguém pode estar seguro de "saber do que se fala", porque esses objetos estão inscritos em uma filiação e não são produto de uma aprendizagem. A AD e o inconsciente estão explicitamente articulados por Pêcheux:

...todo discurso marca a possibilidade de uma desestruturação-reestruturação dessas redes e trajetos: todo discurso é o índice potencial de uma agitação nas filiações sócio-históricas de identificação, na medida em que ele constitui ao mesmo tempo um efeito dessas filiações e um trabalho (mais ou menos consciente deliberado, construído ou não, mas de todo modo atravessado pelas determinações inconscientes) de deslocamento no seu espaço... (PÊCHEUX, 2012, p. 56; grifos meus)

Como ressalta Carvalho (2013), a interpretação, por estar imersa no campo da linguagem e do discurso, não tem como referência o falso e o verdadeiro, tomando distância

\footnotetext{
6 "Coisas-a-saber": expressão de Pêcheux para se referir à falta estrutural do ser falante, ao real (no sentido de Lacan) como impossível. As "coisas-a-saber" são um resto irredutível.
} 
das proposições positivistas da ciência. Pêcheux (2012) comenta criticamente o uso regulado de proposições lógicas (verdadeiro ou falso) com interrogações disjuntivas ("o estado das coisas" é A ou não A?) presente nas técnicas materiais e nas técnicas de gestão social dos indivíduos no mundo moderno: marcá-los, identificá-los, classificá-los, compará-los, colocálos em ordem, em colunas, em tabelas, reuni-los e separá-los segundo critérios definidos, etc. Para o autor, esses espaços de coerção lógica disjuntiva repousam, em seu funcionamento discursivo interno, sobre uma proibição da interpretação e, correlativamente, sobre a recusa de certas marcas de distância discursiva, tais como "em certo sentido", "se se desejar", "se podemos dizer", "em um grau extremo", etc. Parafraseando Pêcheux (2012, p. 33), trata-se da recusa de quaisquer aspas de natureza interpretativa, o que implica colocar em jogo "uma bipolarização lógica das proposições enunciáveis com o sentimento insidioso de uma simplificação unívoca." A subjetividade, na estrutura social pós-moderna, é então reduzida a uma evidência numérica, tal como antecipou Pêcheux.

Em Meu ensino, sua natureza e seus fins, Lacan também (2006) estabelece algumas reflexões entre a questão da emergência do sujeito e sua relação com o discurso da ciência. Trata-se de uma intervenção proferida no ano de 1968, exatamente antes do emblemático mês de maio. Sobre a Psicanálise, Lacan assim se expressa: "Salta aos olhos que é uma operação de discurso, uma operação-discurso. [...] Ninguém esperou a análise para se interessar pelo discurso. Foi inclusive dele que partiu tudo que é ciência." (LACAN, 2006, p. 82, grifos meus) A Análise do Discurso, disciplina surgida nesse mesmo período histórico, encontra-se assim, nas palavras de Lacan, imbricada à Psicanálise, à questão do sujeito e às questões colocadas sobre a emergência do discurso da ciência.

Posteriormente, em uma conferência proferida em janeiro de 1972, Lacan (2011) reinvoca as consequências da aliança entre o discurso da ciência e do discurso do capitalista, o que culminou no "momento contemporâneo do rigor positivo" na constituição das ciências, conforme foi trabalhado por Pêcheux em sua última obra. Em uma frase que se tornou frequentemente citada e que é diretamente trabalhada por Pêcheux em $O$ Discurso: Estrutura ou Acontecimento, Lacan afirma que "O que distingue o discurso do capitalismo é isto: a Verwerfung $^{7}$, a rejeição para fora de todos os campos do simbólico, com as consequências de que já falei - rejeição de quê? Da castração." (LACAN, 2011, p. 88). Pêcheux retoma esse enunciado de Lacan ao pé da letra em sua última obra, buscando retirar as consequências que ele implica para o universo do discurso no mundo contemporâneo. Em suas palavras, "As 'coisas-a-saber' representam assim tudo o que arrisca faltar à felicidade [...] do 'sujeito pragmático'..." (PÊCHEUX, 2012, p. 34). Conforme foi visto anteriormente, o autor coloca em primeiro plano o que chamou de reconhecimento de um fato estrutural próprio à ordem humana: a "castração simbólica". Dessa forma, Pêcheux, amparado em Lacan, denuncia em sua última obra que a $\mathrm{AD}$ que se dirige ao mundo contemporâneo recolhe os efeitos na civilização da trama discursiva nascida da conjunção entre o discurso da ciência e o discurso do capitalismo.

Aliás, o "pragmatismo do sujeito contemporâneo", objeto de um debate atual entre os psicanalistas, foi evocado por Pêcheux três décadas antes. $\mathrm{O}$ autor se interessou pelo real da estrutura do discurso, pelo inassimilável, por aquilo que ameaça a estabilidade do sujeito

\footnotetext{
7 Verwerfung: termo usado por Freud para significar "rejeição", "expulsão" de uma determinada representação ou percepção da realidade. Lacan elevou a Verwerfung à dignidade de conceito, nomeando-a de forclusão.
} 
pragmático e que produz efeitos de sujeito. Em suas palavras anteriormente evocadas: "há real, isto é, pontos de impossível." (PÊCHEUX, 2012, p. 29). A esse respeito, afirma o autor:

Interrogar-se sobre a existência de um real próprio às disciplinas de interpretação exige que o não-logicamente-estável não seja considerado a priori como um defeito, um simples furo no real. É supor que - entendendose o "real" em vários sentidos - possa existir um outro tipo de real diferente dos que acabam de ser evocados, e também um outro tipo de saber, que não se reduz à ordem das "coisas a saber" ou a um tecido de tais coisas. Logo: um real constitutivamente estranho à univocidade lógica, e um saber que não se transmite, não se aprende, não se ensina, e que, no entanto, existe produzindo efeitos. (PÊCHEUX , 2012, p. 43; grifos meus)

$\mathrm{Na}$ nota ao leitor do último trabalho de Pêcheux (2012), Orlandi fundamenta o dispositivo de análise e de interpretação da AD como uma forma de conhecimento que se faz no entremeio e que leva em conta a contradição entre sua (de Pêcheux) teoria e sua prática de análise. O próprio Pêcheux evoca três caminhos: “... o do acontecimento, o da estrutura e o da tensão entre descrição e interpretação no interior da análise do discurso." (PÊCHEUX, 2012, ps. 18-19; grifos meus).

A verdade, dessa forma, é uma decorrência e não um atributo da interpretação, e só pode ser verificada a posteriori por aquilo que a interpretação desencadeia. Ela aloja por estrutura a dimensão de um impossível de se dizer que é rejeitado pelo discurso da ciência e pelo discurso do capitalista. Pêcheux (2012) frisa esse impossível do real, aquilo que "não pode não ser assim", ao sustentar que há independência do objeto face a qualquer discurso feito a seu respeito.

\section{Considerações finais}

O percurso teórico e historiográfico apresentado e problematizado no decorrer deste artigo aponta para uma confluência entre a Análise do Discurso Francesa e a psicanálise de orientação lacaniana, e interroga sobre a possiblidade de trabalho no campo da subjetividade no contexo da pós-modernidade do século XXI. É conhecido o fato de que a articulação entre discurso e psicanálise é um direcionamento epistemológico que se encontra na própria fundação da disciplina por Pêcheux em 1969. Nesse horizonte teórico interdisciplinar, solidificado e retrabalhado no decorrer das últimas décadas, o apelo à singularidade do sujeito, que implica o reconhecimento de sua subjetividade intrínseca, surge como uma resposta diante da "dominação combinada" entre o discurso da ciência e o discurso do capitalismo na contemporaneidade, dominação que toca e afeta diretamente a questão sobre o sujeito. O "cientificismo" e o "momento contemporâneo do rigor positivo", expressões de Pêcheux trabalhadas no decorrer deste artigo, aliados à crença no "sofisma das bases biológicas", expressão de Ansermet, são uma evidência do tratamento homogeneizante dado à subjetividade no mundo atual. Nesse sentido, a Análise do Discurso pode se valer desta reflexão para a renovação e atualização de sua condição de discurso, sem perder de vista o sujeito concebido como "efeito de linguagem", sujeito este sempre singular. Nas palavras de Lacan, em uma reflexão sobre o homem moderno: 
No homem "liberado" da sociedade moderna, eis que esse despedaçamento revela, até o fundo do ser, a sua pavorosa fissura. (...) É essa vítima comovente, evadida de alhures, inocente, que rompe com o exílio que condena o homem moderno à mais assustadora galé social, que acolhemos quando ela vem a nós; é para esse ser de nada que nossa tarefa cotidiana consiste em reabrir o caminho de seu sentido, numa fraternidade discreta em relação à qual sempre somos por demais desiguais. (LACAN, 1998, p. 126)

\begin{abstract}
This article intends to problematize an interface between Michel Pêcheux's intervention in 1983 (The discourse: structure or event) and some contemporary psychoanalytic questions about the effects of the "combined domination" of two discourses: the discourse of science and the discourse of capitalism. Pêcheux, in a dialogue with psychoanalysis, problematizes the consequences of this discursive combination, denouncing as effect a logical instability of the singularity of the subject. This pragmatism of the contemporary subject seeks to erase its structuring singularity. For Ansermet, a French psychoanalyst, this neo-positivism forms one of the greatest epistemes of our time. Ansermet, as Pêcheux did three decades earlier, places the center of this debate in contemporary scientism. In this way, certain points of the last theoretical construction of Pêcheux that legitimize the interface between the discursive and psychoanalytic fields are illuminated, as well as points of the Pêcheutian reflection that problematize the question of scientism today.
\end{abstract}

Keywords: Discourse. Psychoanalysis. Subject. Singularity.

\title{
Referências
}

ANSERMET, F. (2013) Elogio do incomensurável. In: Revista Curinga: Ciência corpo e real. Belo Horizonte, v. 36, p. 37-50, 2013.

AZEVEDO, A. V. (2010) Análise leiga: mais, ainda. In: JORGE, M. (org.). Lacan e a formação do psicanalista. Rio de Janeiro: Contra Capa, 2010. p. 67-77.

BROUSSE, M. H. (2013) Ressonâncias do VIII Congresso da AMP: "A ordem simbólica no século XXI não é mais o que era. Que consequências para a cura?” In: Revista Curinga 36: Ciência corpo e real. Belo Horizonte, v. 36, p. 67-74, 2013.

BRUSA, L. (2014) Encontros do real. In: Um real para o século XXI. Belo Horizonte: Scriptum, 2014. p. 130-132.

CARVALHO, F. F. (2013) Psicanálise e ciência: o real em jogo. Revista Curinga 36: Ciência corpo e real. Belo Horizonte: Scriptum, 2013.

GADET, F. et alii. (1990) Apresentação da conjuntura em linguística, em psicanálise e em informática aplicada ao estudo dos textos na França, em 1969. In: GADET, F.; HAK, T.. (orgs.). Por uma análise automática do discurso: uma introdução à obra de Michel Pêcheux. Campinas: Ed. Unicamp, 1990. p. 39-57. 
HENRY, P. (1990) Os fundamentos teóricos da "Análise Automática do Discurso" de Michel Pêcheux (1969). In: GADET, F.; HAK, T.. (orgs.). Por uma análise automática do discurso: uma introdução à obra de Michel Pêcheux. Campinas: Ed. Unicamp, 1990. p. 13-38.

LACAN, J. (2011) Estou falando com as paredes. In: Estou falando com as paredes. Rio de Janeiro: Jorge Zahar, 2011. p. 73-99. (2006) Meu ensino, sua natureza e seus fins. In: Meu Ensino. Rio de Janeiro: Jorge Zahar, 2006. p. 69-100.

(1988) A agressividade em psicanálise. In: Escritos. Rio de Janeiro: Jorge Zahar, 1998. p. 104-126. 892. (1988) A ciência e a verdade. In: Escritos. Rio de Janeiro: Jorge Zahar, 1998. p. 869-

MAINGUENEAU, D. (1990) Análise do Discurso: A questão dos fundamentos. In: Caderno de estudos linguísticos. Campinas, v.19, p. 65-74, 1990.

MAURANO, D. (2010) Um estranho no ninho ou a psicanálise na universidade. In: JORGE, M. (org.). Lacan e a formação do psicanalista. Rio de Janeiro: Contra Capa, 2010. p. 209227.

ORLANDI, E. P. (1994) O lugar das sistematicidades linguísticas na Análise de Discurso. In: Revista DELTA. São Paulo, v. 10, p. 295-307, 1994.

PÊCHEUX, M. (2012) O discurso: estrutura ou acontecimento. Campinas: Pontes, 2012.

[ ] (1990) Análise Automática do Discurso. In: GADET, F.: HAK, t. (orgs.). Por uma análise automática do discurso: uma introdução à obra de Michel Pêcheux. Campinas: Ed. Unicamp, 1990. p. 61-161.

PÊCHEUX, M. FUCHS, C.A (1990) propósito da Análise Automática do Discurso. (A AD69). In: GADET, F.: HAK, t. (orgs.) Por uma análise automática do discurso: uma introdução à obra de Michel Pêcheux. Campinas: Ed. Unicamp, 1990. p. 163-252.

PÊCHEUX, M. (1988) Semântica e discurso: uma crítica à afirmação do óbvio. Campinas: Ed. Unicamp, 1988. 